\title{
Robotics and Its Effects on the Educational System of Montenegro
}

\author{
Branko Anđić ${ }^{1, *}$, Rade Grujičić ${ }^{2}$ Marina Mijanović Markuš $\breve{2}^{2}$ \\ ${ }^{1}$ Elementary School "Radojica Perović", Podgorica, Montenegro \\ ${ }^{2}$ Faculty of Mechanical Engineering Podgorica, University of Montenegro, Montenegro \\ *Correspondence: Faculty of Mechanical Engineering Podgorica, University of Montenegro, Montenegro. E-mail: \\ marinami@ac.me
}

Received: June 11, 2015

Accepted: July 8, 2015 Online Published: July 20, 2015

doi:10.5430/wje.v5n4p52

URL: http://dx.doi.org/10.5430/wje.v5n4p52

\begin{abstract}
The paper presents the results of research conducted among students of primary and secondary schools in Montenegro about robotics and its place in Montenegrin educational system. Survey was used as a data collecting method in the study and the results were obtained using theoretical analysis. Attitudes of Montenegrin students were compared with similar studies conducted in the world. It was undisputed that the Montenegrin school students showes great interest in acquiring knowledge in field of robotics. Elementary school students gained their first knowledge of mechatronics during preparation for the competition "First Lego League" (FLL), while high school students got knowledge through preparations for the competition "First Tech Challenge" (FTC). The aim of study was to introduce views and proposals of students related to the further development of the teaching process in the field of robotics.
\end{abstract}

Keywords: Robotics, Mechatronics, First Lego League, First Tech Challenge, The Teaching Process

\section{Introduction}

\subsection{Mechatronics in Education}

Robots are machines which were constructed by human in order to carry out a variety of tasks. These are electromechanical devices, autonomous or semi-autonomous, originally developed for industrial purposes to facilitate demanding jobs or accelerate more accurate realization of the projects. Eventually the robots were started taking more and more dominant role in the industry, as well as in other spheres of human activity. Artificial intelligence distinguishes robots from other machines. Due to the rapid development of robotics and its spread to different areas of social life, the robots do not represent more a "great unknown" and become a part of everyday life. Basic knowledge of mechatronics, automation, management and robotics can be acquired through all levels of education, starting from elementary. Therefore, in addition to the original purpose, which was reflected in replacing human in the performance of certain tasks, robotics in recent times awakes creativity and interest of young people and very often gets and entertaining character. Frequent exhibitions and competitions in the field of robotics are being organised among young people, so there have been various competitive disciplines such as Air Race, Line Follower, Puck Collect, Humanoid Sprint, Robot Sumo, Robot Maze, First Lego League, First Tech Challenge, Ring it Up, Eurobot, Freestyle... Robotics is a young multidisciplinary science which deals with research, development, designing, programming, production and use of robots. It it based on some natural sciences such as mathematics, physics, mechanics and others, as well as the applied sciences such as mechanical engineering, electrical engineering, computer science. As robotics is multidisciplinary science, the key paradigm of mechatronic education intelligently connect multiple scientific disciplines (Gómez-de-Gabriel, J., 2001). Children in primary schools have unrealistic attitudes about robots formed on the basis of images you luck in films, non-specialist journals and books (Ilieva V., 2010). Therefore, the formation of a scientific view of the world is one of the main tasks of educational work. Construction of scientific research attitude in the field of mechatronics would lead to greater student interest about the natural science. Gaining student knowledge through the prism of science would lead to more rapid modernization of scientific programs and increasing interest children in science. Robots as instructional assistants or learning companions may enhance students' motivation and learning performance (Barker \&Ansorge, 2007). The introduction of robotic subject matter in high schools curriculum would significantly modernize the teaching process. In the classroom, some educators have used robots as a tool to assist in the teaching of actual programming languages 
(Barnes, 2002). Through the construction and programming of robots students gain experience in solving problems (Nourbakhsh et al., 2005). The quality of teaching would improve, because a well-organized, obvious and meaningful teaching, with a high level of correlation between the courses, which would be performed with the most modern teaching resources and deal with current issues, would develop a desire in students to learn something that they need in the future (Mijailovic S. and D. Golubovic 2010).

Learning through robotics is a "learning through building" and increases the motivation of students for obtaining knowledge (Kafai\&Resnick, 1996; Papert, 1993; Harel\&Papert, 1991). In addition, world wide research has shown that attending mechatronics classes and construction of robot affects on students in order to better understand the basic physiological processes and biodiversity and get them more interested in the teaching of biology, ecology and psychology (Miglino, Lund \&Cardaci, 1999). Robotics and Mechatronics stimulate children with special educational and cognitive needs learning process (Chu et al., 2005). Previous research has shown that the inclusion of robotics improves the overall educational process at all stages (Bauer \& Gallagher, 2003). Through this actual doing process, students can be inspired and motivated to recognize that what they learn in the school can relate to their current and future lives and contribute to meeting many of the major challenges that confront society today (Y.-L. Chang \& H.-H. $\mathrm{Wu}, 2015)$.

Students who have experience in the field of robotics have a higher degree of application theoretical knowledge in practice (Sullivan \& Moriarty, 2009).

The idea of involving mechatronics and programming of robots in teaching appeared more than 30 years ago (Miglino, Lund \&Cardaci, 1999; Papert, 1980).

\subsection{Basic Parts of the Robot}

Previous studies in the field of mechatronics recommend the use Lego Mindstorm NXT robot in the process of educating students in elementary and secondary schools (Gómez-de-Gabriel, J. et al. 2011). Therefore, this paper provide an overview of the basic characteristics of the Lego Mindstorm NXT robot. A control unit, three servo motors, ultrasonic sensors, two touch sensors, light and sound sensors, present basic components that Lego Mindstorm NXT package consists (Hystad, 2002). The control unit is an intelligent, programmable unit of Mindstorms robots. It contains the interfaces used to connect servo motors and sensors.

The upper side of the control unit contains the LCD display resolution of 100x64 pixels. It provides browsing the list of program files uploaded from PC. Servo motors provide the movement of the robot. They are consisted of motors, gears, head servo motor and rotary sensors. Sensors measure the rotation accuracy of $1^{\circ}$. The motor speed can be adjusted individually for each engine, and their programming is done by defining the rotation angle, speed, time constraints or according informations collected and sent by sensor. The ultrasonic sensor measures the distance of an object and sends information about it to the NXT control unit. Usage of ultrasonic sensor makes robot orientation in space easier. Touch sensor is activated in the event of contact with the object at close range and can be considered as a switch which causes a further robot activity.

Information about intensity of light reflected from the substrate NXT control unit receives by the sensor based light. Sound sensor represents, in some way, the robot's sense of hearing and enables him to communicate easier with the environment. The robot moves independently over substrate owing to external landmarks and internal stimuli that are pre-programmed. Making programs for NXT Mindstorm is simple and reflected in stacking programmed blocks. It is the simplicity and user-friendliness, which are the basic features of programming NXT controller, children stimulate interest in programming and in an obvious way of introducing them into its basis.

The aim of this study was to analyze the attitudes, knowledge and Montenegrin schools students' interests in robotics, as well as to encourage the further development of the teaching process in this area.

\section{Method}

The subject of this study is analysis of the position of Robotics - Mechatronics in contemporary teaching in primary and secondary schools in Montenegro. Method of theoretical analysis, which was used in this research, processed the data acquired on robotics in our schools and contemporary scientific literature on the educational situation of robotics in other countries. The Method of theoretical analysis are processed on the current literature, which gives an overview of the discussion. The instrument used in the study was a survey that was conducted with students in primary and secondary schools in Montenegro who had experience in the field of robotics. The survey consist 14 questions, of which 8 closed type and 6 opened type. 48 students were interviewed, which is almost the total number of students in primary and secondary schools in Montenegro who had the opportunity to design some robots. The 
survey results are presented in table 1.

\section{Results}

The opinions about robotics expressed in the poll by the students of primary and secondary schools are presented in Table 1.

Table 1. Results of the Survey on the Position of Robotics in Montenegrin Schools According to Students (the evaluation ratings are: $5=$ Excellent, $4=$ Good, $3=$ Average, $2=$ Below Average, $1=$ Poor)

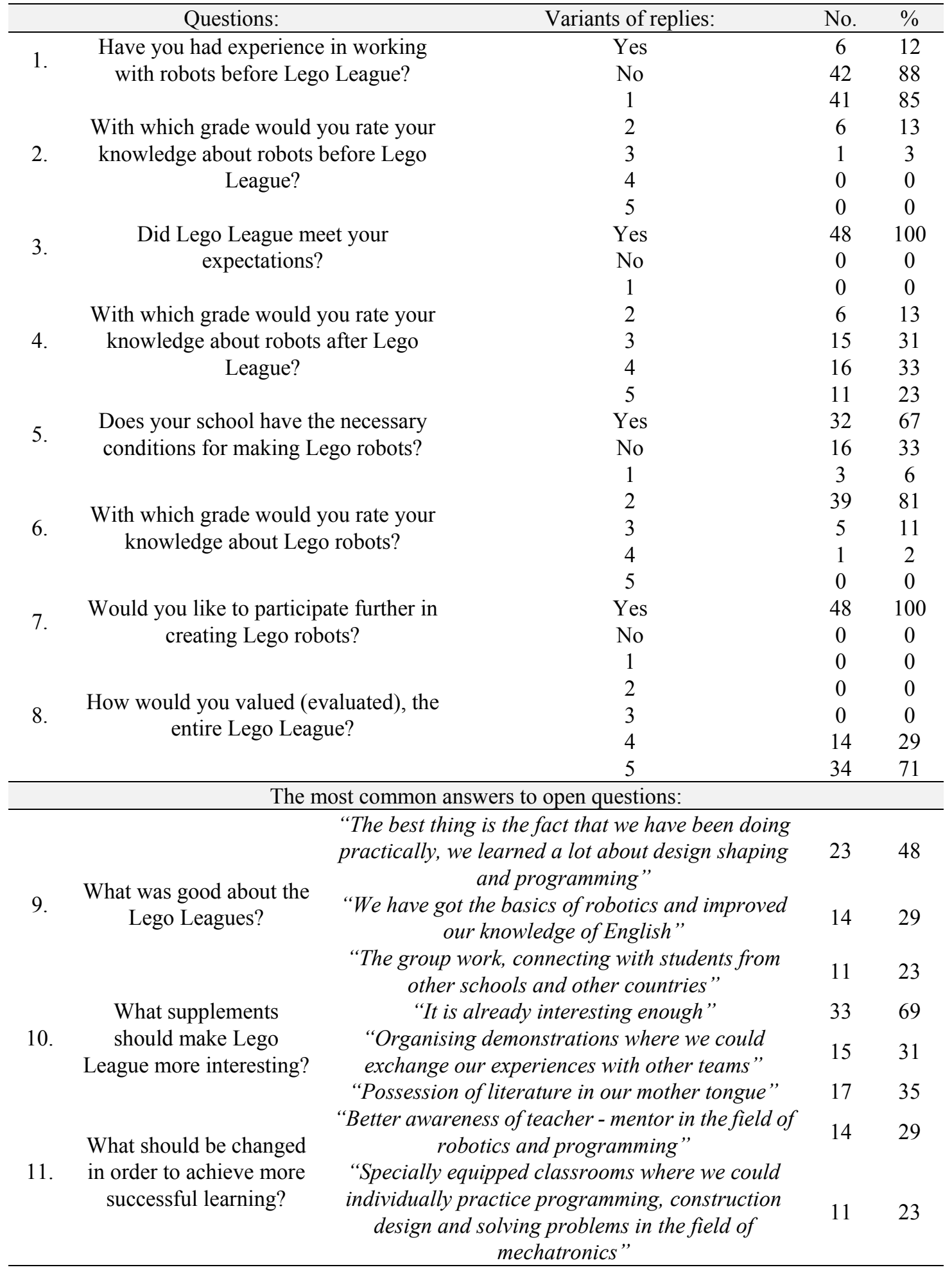




\begin{tabular}{|c|c|c|c|c|}
\hline & & $\begin{array}{c}\text { "Purchasing more Lego packages and forming } \\
\text { multiple teams within a school" }\end{array}$ & 6 & 13 \\
\hline \multirow[t]{2}{*}{12.} & $\begin{array}{l}\text { What are the difficulties } \\
\text { you have had in }\end{array}$ & $\begin{array}{l}\text { "The lack of materials, parts, which is why we } \\
\text { couldn't improve the construction of the robot" }\end{array}$ & 31 & 65 \\
\hline & designing Lego robot? & $\begin{array}{l}\text { "We had no prior knowledge of programming" } \\
\text { "Organising some lectures where we can get }\end{array}$ & 17 & 35 \\
\hline \multirow[t]{2}{*}{13.} & $\begin{array}{l}\text { Suggestions about } \\
\text { further working } \\
\text { methodology? }\end{array}$ & $\begin{array}{c}\text { acquainted with the basics of programming and get } \\
\text { directions for finding literature or websites that } \\
\text { would help us in learning" }\end{array}$ & 29 & 63 \\
\hline & & $\begin{array}{c}\text { "You should build in robotics as an optional or a } \\
\text { regular subject in schools" }\end{array}$ & 19 & 37 \\
\hline \multirow{2}{*}{14.} & What are the lacks of & "No lacks" & 36 & 75 \\
\hline & $\begin{array}{c}\text { preparation for the Lego } \\
\text { competition? }\end{array}$ & "Insufficient funds to purchase materials" & 12 & 12 \\
\hline
\end{tabular}

The survey results showed that students of Montenegrin schools first knowledge in the field of robotics acquire during preparation for the FLL competition in primary or during the preparation for FTC competition in secondary schools.

\section{Discussion}

After Interviewed students pleaded their knowledge in the field of robotics before preparing for the competition was unsatisfactory and evaluated by an average score of 1.15. Also their peers in Europe acquire their first experience in field of robotics with the help of Lego robots (Ilieva, 2010). Competition in this area (FLL and FTC) has met the expectations of all surveyed students $48(100 \%)$. Students attitude is that their knowledge in the field of robotics was significantly increased during practical work and preparation for the competition and their knowledge was assessed an average score of 3.70. Rating by which respondents (students) evaluated increase of their knowledge after the event corresponded to the percentage increase of knowledge in the field of robotics which is predicted by the evaluation the First Lego League envisioning the scaling up knowledge of at least $75 \%$ (Melchior A. et al, 2005). While $32(67 \%)$ students believe that their school had all the necessary conditions for work in the field of robotics, $16(33 \%)$ students had opposite opinion. According to the fact that all schools receive the main designing parts from the organizers, it is understandable why a large number of students considered to have had a complete material to work with. Average grade of 2.10 students have evaluated the knowledge of their teachers-mentors in the field of robotics. Taking into account that the expertise is of one of the basic characteristics of a successful teacher, it is necessary to organize additional training of teaching staff from the fields of robotics. Topics in the field of mechatronics is necessary to be included in program of professional training of teachers in Montenegro if we want them to supplement and refine their knowledge about robotics. Teachers who use integration of robotics and mechatronics processes in educational activity should continuously improve their own knowledge in cooperation with the mechatronics studies at university level of education (Chambers \&Carbonaro, 2003; Sullivan \& Moriarty, 2009). There was no adequate staff in the field of robotics in Montenegro until now, but the need for monitoring of global flows caused the formation such a study program - Mechatronics at Faculty of Mechanical Engineering in Podgorica. All 48 students (100\%) evaluated FLL-FTC competition with 5 and expressed a desire to continue to engage in the process of working in the field of robotics. Based on the foregoing, it can be concluded that there is great interest in acquiring knowledge in the field of mechatronics between the students in Montenegrin schools. A similar attitude that robotics is very attractive and interesting science have students from Serbia (Mijailović, 2010).

As a major strength FLL and FTC, $23(48 \%)$ of students considered the possibility to practically apply their knowledge, 14 (29\%) stated that it is important to have mastered knowledge of the English language, while 11 (23\%) believe that connecting schools in Montenegro, as well as those from abroad, is the best part of these events. The fact that the practical application of knowledge to students who come mainly independently one of the main features of robotics as a science was concluded in a similar survey conducted by Bers et al 2002 (Bers et al. 2002). A large number of students $33(69 \%)$ believes that the competition was very interesting, while 15 of them (31\%) thought that it would be desirable to organize a large number of magazine review of robots and robotics in our country so that students and tutors were able to share knowledge and experience. $17(35 \%)$ of students believe that the possession of literature in our language would increase the level of their acquired knowledge, while $14(29 \%)$ of them felt that better ople of teacher-mentors would help students in learning; $11(23 \%)$ students think that owning a specially 
equipped classrooms where they could practice programming and construction would have a positive impact on their knowledge, $6(13 \%)$ of students stated the necessity of owning more Lego packages within a school to enable exercise and relieved work. Opinions of students in Montenegrin schools are consistent with research conducted on "Frederick University" Cyprus, which states that the process of acquiring new knowledge in the field of robotics could be successfully implemented if the single robot working group of 4 students (Georgios A. Demetriou, 2011).

Students who are preparing for competitions in the field of robotics have the following problems - the lack of material for a complete upgrade of the robot and the lack of knowledge about programming. In order to solve these problems, $29(63 \%)$ of the surveyed students propose organising lectures where students would be introduced with basis of robotics and directed on further resources that can help them, while others, 19 of them (27\%), proposes the introduction of robotics as an elective subject in primary and secondary schools in Montenegro. Research in Serbia yielded similar results, where it is proposed the introduction of robotics into the curriculum of secondary school (Mijailović et al., 2010). 36 (75\%) students believe that the FLL and FTC have no scarcities, while 12 of them (25\%) cited a lack of funds for the procurement of parts as a major brake in both contests.

In the teaching process in primary schools of Montenegro there is no possibility for students to attend the mechatronics as an obligatory or an optional course, while only a small number of students have the opportunity to acquire knowledge within extracurricular activities during preparations for the First Lego League. However, pupils in secondary schools have a choice of mechatronics as an optional course, except gymnasium that still does not provide the choice of robotics as an optional subject.

The results of the questionnaire which included 48 primary and secondary schools in Montenegro who have had the opportunity to acquire basic knowledge in the field of robotics, showed student's great interest in this scientific field. First practical knowledge in the field of robotics students of Montenegrin schools get during the preparation for the competition "First Lego League" (FLL) in the primary or "First Tech Challenge" (FTC) in secondary schools. Students graded with average score of 1.15 their knowledge in the field of robotics before preparing for the competition (FLL and FTC) and they considered that their knowledge has increased a lot, so it is now graded with average score of 3.70. Knowledge of their mentors, in this area, students graded with an average score of 2.10. They also considered that their acquisition of knowledge would be greatly facilitated if teachers were better informed about this area. All the surveyed students considered that the competitions are interesting enough. Practical application of acquired knowledge students emphasize as their main advantage. As the main difficulties in the work, they point out the lack of professional literature in our language and lack of availability of materials. As a suggestion for better acquisition of knowledge in this field, students suggest introducing robotics as an elective subject in schools and the establishment of special cabinet in which classes would be conducted in this scientific field.

Due to the fact that students in Montenegrin schools showed great interest in robotics, it is necessary not only to include this scientific field in the curriculum for primary and secondary education, but also organize training of the teachers who implement a quality educational process in schools.

This paper presents a pioneering study on the position of robotics in primary and secondary education in Montenegro and it is based on the attitudes of students as the main subjects of the teaching process.

\section{References}

Barker, B. S., \& Ansorge, J. (2007). Robotics as Means to Increase Achievement Scores in an Informal Learning Environment. Journal of Research on Technology in Education, 39(3), 229-243. http://dx.doi.org/10.1080/15391523.2007.10782481

Barnes J. David. (2002). Teaching Introductory Java through LEGO Mindstorms Models. Proceedings of the 33rd SIGCSE Technical Symposium on Computer Science Education.

Bauerle, A., \& Gallagher, M. (2003). Toying With Technology: Bridging the Gap Between Education and Engineering. In C. Crawford et al. (Eds.), Proceedings of Society for Information Technology \& Teacher Education International Conference, (pp. 3538-3541) Chesapeake, VA: AACE

Bers, M.U., Ponte, I., Juelich, C., Viera, A., \& Schenker, J. (2002). Teachers as Designers: Integrating Robotics in Early Childhood Education. Information Technology in Childhood Education Annual, 2002(1), 123-145.

Chambers, J.M., \& Carbonaro, M. (2003). Designing, Developing, and Implementing a Course on LEGO Robotics or Technology Teacher Education. Journal of Technology and Teacher Education, 11(2), 209-241.

Chang, Yu-Liang \& Wu Huan-Hung. (2015). A Case Study of Increasing Vocational High School Teachers Practices 
in Designing Interdisciplinary Use of Scientific Inquiry in Curriculum Design. Eurasia Journal of Mathematics, Science \& Technology Education, 11(1), 37-51.

Chu, K.H., Goldman, R., \& Sklar, E. (2005). RoboXAP: an agent-based educational robotics simulator. In Agent-based Systems for Human Learning Workshop (ABSHL) at AAMAS-2005.

Georgios A. Demetriou, (2011). Mobile Robotics in Education and Research. Retrived from http://faculty.uscupstate.edu/svandelden/courses/current/sds2011_2012/intech_article

Gómez-de-Gabriel J.M., Víctor F Muñoz, Fernandez-Lozano, Garcia- Morales, R Molina-Mesa, C Perez-del-Pulgar, J Seron-Barba \& M Azouaghe. (2001). "Design and control of a robotic assistant for laparoscopic surgery". Proceedings of the International symposium on intelligent robotic systems.

Gómez-de-Gabriel, J.M., Mandow, A., Fernández-Lozano, J., \& García-Cerezo, A.J. (2011). Using Lego NXT Mobile Robots With LabVIEW for Undergraduate Courses on Mechatronics. IEEE Transactions on Education, 54(1), 41-47. http://dx.doi.org/10.1109/TE.2010.2043359

Harel, I. (1991). Children designers: Interdisciplinary constructions for learning and knowing mathematics in a computer-rich school. Norwood, NJ: Ablex Publishing.

Hystad Dean. (2002). Building LEGO Robot For First Lego League. Minnesota, MN: INSciTE.

IlievaVessela. (2010). "Robotics in the Primary School - how to do it?". Proceedings of the SIMPAR 2010 Workshops Intl. Conf. on simulation, modeling and programming for autonomous robots Darmstadt (Germany). November 2010, pp. 596-60 ISBN 978-3-00-032863-3

Kafai, Y., \& Resnick, M. (1996). Constructionism in Practice: Designing, Thinking, and Learning in a Digital World. Mahwah, NJ: Lawrence Erlbaum.

Melchior, Alan L., Cutter, T., \& Cohen, F. (2005). More than Robots: An Evaluation of the First Robotics Competition Participant and Institutional Impacts. Waltham, MA Center for Youth and Communities, Brandeis University.

Miglino, O., Lund, H.H., \& Cardaci, M. (1999). Robotics as an Educational Tool. Journal of Interactive Learning Research, 10(1), 25-47.

Mijailović Snežana \& Golubović Dragan. (2010). "Robotika u nastavi računarstva i informatike u gimnaziji”. Proceeding of the Technical Faculty Čačak-3rd International Conference, May 2010., UDK: 007.52:373.5.

Nourbakhsh, I., Crowley, K., Bhave, A., Hamner, E., Hsium, T., Perez-Bergquist, A., Richards, S., \& Wilkinson, K. (2005). The robotic autonomy mobile robots course: Robot design, curriculum design, and educational assessment. Autonomous Robots, 18(1), 103-127. http://dx.doi.org/10.1023/B:AURO.0000047303.20624.02

Papert, S. (1980). Mindstorms: Children, Computers, and Powerful Ideas. NY, New York: Basic Books. http://dx.doi.org/10.1007/978-3-0348-5357-6

Papert, S. (1993). Instructionism versus Constructionism. In The Children's Machine: Rethinking school in the age of the computer. NY: Basic Books. http://dx.doi.org/10.1007/978-3-0348-5357-6

Sullivan, F.R., \& Moriarty, M.A. (2009). Robotics and Discovery Learning: Pedagogical Beliefs, Teacher Practice, and Technology Integration. Journal of Technology and Teacher Education, 17(1), 109-142.

Van der Geer, J., Hanraads, J. A. J., \& Lupton R. A. (2000). The art of writing a scientific article. Journal of Scientific Communications, 163, 51-59. 